\title{
A SIGNAL PROCESSING METHODOLOGY FOR ASSESSING THE PERFORMANCE OF ASTM STANDARD TEST METHODS FOR GPR SYSTEMS
}

\author{
Francesco Benedetto ${ }^{1, *}$, Fabio Tosti ${ }^{2}$
}

\begin{abstract}
${ }^{1}$ Signal processing for Telecommunications and Economics Lab., Roma Tre University, Via Vito Volterra 62, 00146, Rome, Italy; e-mail: francesco.benedetto@uniroma3. (*Corresponding author)

${ }^{2}$ School of Computing and Engineering, University of West London (UWL), St Mary's Road, Ealing, W5 5RF, London, United Kingdom; Fabio.Tosti@uwl.ac.uk
\end{abstract}

\begin{abstract}
Ground penetrating radar (GPR) is one of the most promising and effective nondestructive testing techniques (NDTs), particularly for the interpretation of the soil properties. Within the framework of international Agencies dealing with the standardization of NDTs, the American Society for Testing and Materials (ASTM) has published several standard test methods related to GPR, none of which is focused on a detailed analysis of the system performance, particularly in terms of precision and bias of the testing variable under consideration. This work proposes a GPR signal processing methodology, calibrated and validated on the basis of a consistent amount of data collected by means of laboratory-scale tests, to assess the performance of the above standard test methods for GPR systems. The (theoretical) expressions of the bias and variance of the estimation error are here investigated by a reduced Taylor's expansion up to the second order. Therefore, a closed form expression for theoretically tuning the optimal threshold according to a fixed target value of the GPR signal stability is proposed. Finally, the study is extended to GPR systems with different antenna frequencies to analyze the specific relationship between the frequency of investigation, the optimal thresholds, and the signal stability.
\end{abstract}

Keywords - Ground Penetrating Radar, GPR calibration, performance evaluation, civil engineering application. 


\section{INTRODUCTION}

Ground penetrating radar (GPR) is an increasingly popular non-destructive testing (NDT) technique that emits a short pulse of electromagnetic energy into the subsurface $[1,2]$. When such a pulse strikes an interface between layered materials with different electrical properties, part of the wave reflects back, and the remaining energy continues to the next interface, thereby penetrating in depth before being absorbed. GPR is capable to collect the reflections of the electromagnetic waves at the interface between two different dielectric materials. It is relatively easy to recognize a GPR signal, since the return signal is shaped very similar to the emitted one. The depth, shape and electromagnetic properties of the scattering of the reflecting object affect the time delay, as well as the differences in phase, frequency and amplitude. GPR is a technology with a wide flexibility of usage. It is mainly application-oriented, with structure and electronics relatively variable according to the target characteristics, such as type and constituent materials, the environmental context, and the spatial scale of applications. A variety of areas, e.g., civil and environmental engineering [3], geology, archaeology, forensic and public safety [4], planetary sciences [5] are therefore increasingly interested by the application of this tool.

Nevertheless, few recognised international standards exist in the area of GPR, and a certain amount of inhomogeneous recommendations can be encountered in different countries. Moreover, the levels of knowledge, awareness and experience on the use of GPR may vary very considerably across countries. This results into a general need for the GPR users to know the most appropriate good practices to be followed in terms of GPR measurements and the expected quality level of the results. A small number of National and International standards includes general recommendations for performing geophysical surveys of the subsurface. Many of these focus on civil engineering applications, with the area of transport infrastructures being the most regulated. Within the European framework, few GPR-related National and International guidelines have been issued if compared to the usage of this tool. It is worth to mention the Italian contribution within the field of the underground utility detection [6], along with the guidelines released by IDS 
(Ingegneria dei Sistemi) enterprise [7] and the ASG (Associazione Società di Geofisica) geophysical association [8]. These provide useful theoretical and practical insights on GPR, along with a number of key and application-oriented data processing algorithms. In France, the detection of buried utilities has been thoroughly tackled [9]. In Germany, instructions on the use of radar systems for non-destructive testing in civil engineering [10] and for gaining inventory data of road structures [11] are available. In Scandinavia, recommendations were developed within the Mara Nord Project on the use of GPR in several applications, such as the measurement of air voids in asphalt concrete [12], road construction quality controls [13], bridge deck surveys [14], road rehabilitation projects [15] and in-site investigations [16].

Still at the European level, a number of standards and codes introduced by the European Telecommunications Standards Institute (ETSI) regulate the use of GPR and its emissions of electromagnetic radiation. Such documents focus on the common technical requirements [17], the specific conditions for ground and wall probing radar (WPR) applications [18], the main technical characteristics and test methods [19], the levels of compliance [20] with the Radio and Telecommunications Terminal Equipment (RTTE) Directive [21], as well as with one code of practice in respect of the control, use and application of GPR and WPR systems and equipment [22]. On the other hand, three main standards released by the American Society for Testing and Materials (ASTM) guide the use of GPR toward the investigation of the subsurface [23], the evaluation of asphalt-covered concrete bridge decks [24], and the determination of pavementlayer thickness [25]. In more details, according to the ASTM classification on the standard categories, the above documents can be classified into $i$ ) Standard Guides (i.e., [23]), namely, an organized collection of information or series of options that does not recommend a specific course of action, and ii) Standard Test Methods (i.e., [24] and [25]), wherein specific test procedures for assessing the stability of the GPR signal are discussed, such as the signal-to-noise-ratio (SNR) test. 
Notwithstanding the estimate of the SNR is not new to the GPR community, to the best of our knowledge there are no papers related to the SNR test as defined by the ASTM standards. Many works on signal processing procedures for the assessment and improvement of the SNR in GPR investigations can be found in the literature. In [26], the authors propose to enhance the GPR signal with the Karhunen-Loève transform (KLT), whereas the work in [27] aims at improving the SNR of a GPR signal by introducing an enhanced-signal-based method, with the noise variance being estimated by a clustering technique. Furthermore, a novel pre-processing method for GPR signals, based on the minimum gradient method, is discussed in [28]. Within the most established signal processing techniques performed in the GPR area we can cite time and frequency analyses [29], time varying band-pass filtering [30], deconvolution [31], velocity analysis [32], migration [33] and compressive sensing [34], as well as the attribute analysis and classification [35]. The main purpose of all such techniques is to enhance the SNR of the GPR signal. They commonly focus on the SNR of the received GPR signal, wherein the noise is assumed as the back-scattered noise from the subsurface after carrying out a GPR survey. Conversely, in this paper we are assuming the noise as the amount of clutter that is in the GPR equipment, also known as systematic error. Thereby, we are focusing on the signal stability of a GPR system, during the calibration phase and before an investigation is carried out. The evaluation of this type of internal noise is extremely important to perform automated signal processing by GPR, thereby ensuring that the quality of the GPR waveforms is suited for purposes. According to this, the ASTM standards [23-25] define some tests to verify the stability of the GPR signal, such as the SNR test, and the (short- and long-term) signal stability tests. Notwithstanding their higher scientific level with respect to similar National and International standards, three main failings in the ASTM standards can be singled out, namely, $i$ ) how to select the optimal threshold and to which level of signal accuracy (or stability) this threshold corresponds; $i$ ) the lacking of a detailed analysis of the system performance, particularly in terms of precision and bias of the testing variable under consideration; and iii) the use of a few central frequencies of investigation, which may not allow to supply a comprehensive overview of the 
results in line with the wider range of central frequencies used in GPR applications. To the best of our knowledge, only one paper [36] can be found in the literature wherein the issues in the ASTM standards are tackled by checking the GPR signal stability versus the systematic error of the GPR system. In particular, the paper by Rial et al. [36] represents an effort to set-up a strategy for verifying the stability of performances in GPR systems in terms of the electromagnetic radiated fields. In addition, the paper in [36] focuses on the (short- and long-term) signal stability tests, whereas no discussion has been included about the SNR test. Nevertheless, this activity is dramatically relevant as the starting point to develop a methodology for calibrating GPR devices and verifying proper operation.

In line with the above and according to the guidance provided by the mentioned ASTM standards, this paper is (to the best of the authors' knowledge) the first study that focuses on the ASTM SNR test, thereby aiming at providing a detailed analysis of the bias and variance of the testing variable under consideration (i.e. the SNR). In particular, this work proposes a simple GPR signal processing procedure (calibrated and validated on the basis of a consistent amount of data collected from laboratory-scale tests), to evaluate the precision and bias of the GPR signal under investigation, by a reduced Taylor's expansion up to the second order. Therefore, we propose a closed form expression for theoretically tuning the optimal threshold, according to a fixed target value of the GPR signal stability. Finally, the study is performed with several GPR systems (i.e. exploiting antennas tuned to frequencies different from $1 \mathrm{GHz}$ ), analyzing the specific relationship between the frequency of investigation and the optimal thresholds.

The remainder of this paper is organized as follows. In the first half of Section 2, the GPR working principles as well as the main applications of this NDT are discussed. The second half of Section 2 illustrates the conventional ASTM standard test methods, highlighting the weakness points of such methodologies. In Section 3, a signal processing procedure for threshold tuning is provided, as well as a closed form expression for theoretically evaluating the optimal threshold according to a fixed target level of GPR signal accuracy (or stability). Then, a theoretical analysis 
of the performance of the ASTM test method is developed, in terms of precision and bias of the considered test. The first half of Section 4 describes the laboratory set-up for the GPR measurements, whereas numerical results and comparisons are outlined in the second half of Section 4. Finally, conclusions are briefly drawn in Section 5.

\section{BASIC FRAMEWORK ON GPR PRINCIPLES AND REFERENCE ASTM STANDARDS}

\subsection{GPR working principles and main applications}

The hardware of a GPR system utilized for the measurement of the subsurface conditions usually consists of a transmitter and a receiver antenna, a radar control unit, and suitable data storage and display devices. Measurements can be traditionally performed in two main survey configurations, namely, with ground-coupled or air-coupled antennas, as a function of the main purposes and type of survey.

The working principle of a GPR complies with that of similar electromagnetic devices. It is based on the transmission/reflection of short electromagnetic impulses, with the antenna system being capable to emit and detect them. According to the typical scenario of investigation considered by the ASTM standards analyzed herein, Fig. 1 (a) represents a typical sketch of GPR signal reflections collected with an air-coupled radar system on a multi-layered medium, such as a common flexible pavement structure or an asphalt layer over a bearing concrete substructure. A possible output data coming out from such scenarios is represented by the GPR trace in Fig. 1 (b). In this regard, $R_{A}$ is the surface echo from the air - layer $A$ interface, $R_{\mathrm{B}}$ represents the reflection from the layer $A$ - layer $B$ interface, $R_{\mathrm{C}}$ and $R_{\mathrm{D}}$ are, respectively, the returns from the layer $B-$ layer $C$, and the layer $C$ - layer $D$ interfaces. 

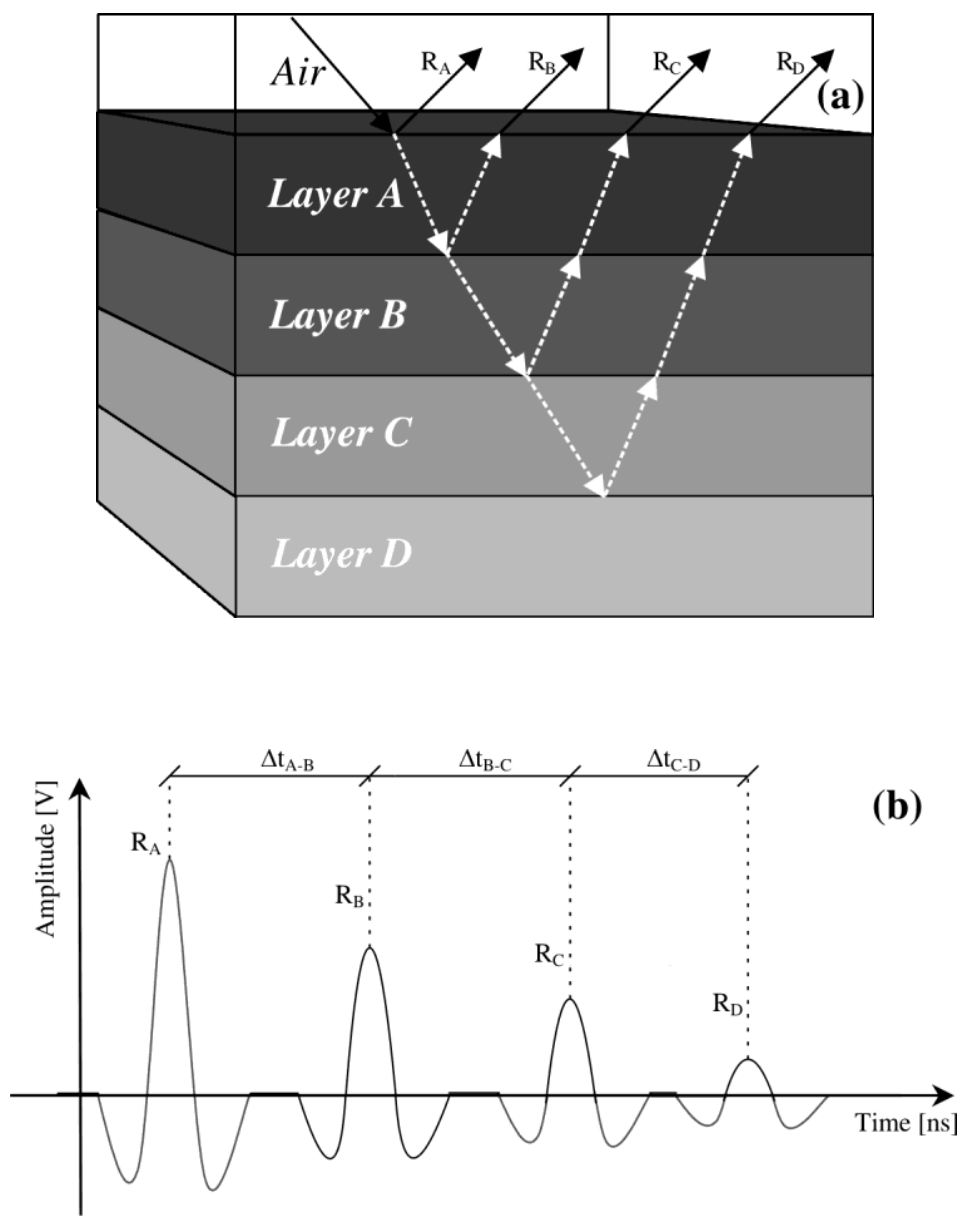

Fig. 1. Typical reflection pattern of a GPR measurement in multi-layered structures with an aircoupled radar system: (a) trend of reflections in a cross-section of a multi-layered structure; (b) sketch of the relevant GPR signal trace.

Overall, the wave propagation velocity $v_{i}$ in a given $i^{\text {th }}$ layer of thickness $h_{i}$, with $i=A, B, \ldots, n$ (being $n$ equal to the number of layers which constitute the system), can be computed as $h_{i}=\left(v_{i}\right.$ $\left.\Delta t_{i \div i+1}\right) / 2$, where $\Delta t_{i \div i+1}$ is the two-way travel time between the pulse reflections of two consecutive layer interfaces. Hence, $v_{i}$ can be estimated by the following relationship:

$$
v_{i}=\frac{c}{\sqrt{\epsilon_{i}}}
$$

where $c$ is the speed of light in the free space and $\epsilon_{i}$ is the relative dielectric permittivity of the investigated medium. Concerning the thickness of layer $A$, its relative dielectric permittivity can be evaluated as follows by means of the so called "Surface Reflection method" [37]: 


$$
\epsilon_{H M A}=\left[\frac{1+A_{R_{A}} / A_{S}}{1-A_{R_{A}} / A_{S}}\right]^{2}
$$

where $A_{R A}$ is the maximum absolute amplitude of the reflected signal from the surface of layer $A$, and $A_{s}$ is the maximum absolute amplitude reflected from a metal plate placed underneath the radar and larger than its footprint, that acts as a perfect electric conductor (PEC). By considering i) the absolute amplitude values from the interface reflections of the underlying deeper layers (i.e. $R_{\mathrm{B}}, R_{\mathrm{C}}$ and $R_{\mathrm{D}}$ in Fig. 1 (b), and $\left.i i\right)$ the retrieved relative permittivity values of each overlying layer $i-1$, it is possible to evaluate the dielectrics of the underlying layers (e.g., [38]).

GPR has found a wide applicability in soil sciences, wherein it is widely used for estimating the subsurface water content during irrigation and drainage cycles [39]. Furthermore, it is employed in Earth sciences for monitoring soils, bedrock, groundwater, and ice [40, 41] and for the management and prevention of natural hazards by ensuring the geotechnical stability of important lifelines, such as road and rail infrastructures [42, 43].

According to the highest amount of guidelines and recommendations specifically dedicated, transport infrastructures can rely on a considerable number of GPR-based applications in the literature ranging from the physical to the geometrical inspections of flexible pavements, bridges and tunnels. To cite a few, we can mention the evaluation of layer thicknesses [44] and subsurface moisture [45, 46], the assessment of damage conditions in hot-mix asphalt (HMA) layers [47], load-bearing layers and subgrade soils [48-51], the inspection of concrete structures [52, 53]. New frontiers on the use of GPR in pavement engineering have been recently tackled on the possibility to infer the strength and deformation properties of road pavements and materials from their electromagnetic characteristics $[54,55]$ and towards the simulation of the GPR signal with respect to typical pavement faults [56]. 


\subsection{ASTM standard test methods}

The ASTM society is an international organization that develops and publishes voluntary consensus technical standards for a wide range of materials, products, systems, and services. To date, about 13000 ASTM standards can be numbered, and three of them are specifically focused on the use of GPR.

The document D6432 - 11 "Standard Guide for Using the Surface Ground Penetrating Radar Method for Subsurface Investigation” [23], deals with the equipment, field procedures, and the interpretation methods for the investigation of the subsurface, and it includes geological, engineering, hydrological, and environmental applications. It provides sections with a thorough terminology about GPR as well as basic algorithms for the estimate of the subsurface electromagnetic parameters, and major signal processing techniques. General and applicationoriented limitations on the use of GPR are also discussed, and instructions on how to perform effectively GPR surveys are given.

The document D4748 - 10 "Standard Test Method for Determining the Thickness of Bound Pavement Layers Using Short-Pulse Radar" [25] applies to the area of pavement engineering and deals with the GPR-based determination of the thickness of bound pavement layers. The standard recommends the use of both ground- and air-coupled radar systems with central frequencies spanning the $1.0-2.6 \mathrm{GHz}$ frequency range, along with the integration with other complementary techniques for georeferencing the data. The layer thickness is here evaluated according to a spacetime relationship complying with (1), and three techniques for the estimate of the relative permittivity, namely, $i$ ) the metal plate calibration, ii) ground truthing by cores, and iii) the Common Midpoint (CMP) method, are discussed. Work instructions, e.g., warm-up and calibration indications, are also provided together with the system limitations and possible interferences occurring to the GPR measurements. Finally, it is argued that it is not possible to 
determine the universal precision and bias statements for the GPR systems and they should be evaluated on a project by project basis.

The document D 6087 - 08 “Standard Test Method for Evaluating Asphalt-Covered Concrete Bridge Decks Using Ground Penetrating Radar" [24] is focused on the detection of concrete or rebar deterioration at or above the level of the top layer of the reinforcing bars, being the process of deterioration mostly due to the action of deicing salts, chloride ions in mix ingredients, or to the inclusion of water. The GPR evaluation procedures here presented apply to the condition of concrete bridge decks overlaid with asphaltic concrete wearing surfaces, bridge decks overlaid with Portland cement concrete, and to bridge decks without an overlay. Such test method is qualified as not suited for evaluating bridges with delaminations localized over the diameter of the reinforcement, or in the case of bridges with cathodic protection installed on the bridge, or for which a conductive aggregate has been used in the asphalt. Concerning the system configuration, the Standard considers both ground-coupled and air-coupled GPR systems, with central frequencies of $1 \mathrm{GHz}$ and greater, and a minimum of $60-\mathrm{dB}$ dynamic range. The calibration procedures for system performance compliance are also discussed, although these are declared as not mandatory to follow and it is argued that "the manufacturer's calibration procedure takes preference". For air-launched antennas, four main tests are mentioned and worthy to be verified, namely, $i$ ) the signal-to-noise ratio (SNR), ii) the signal stability, iii) the linearity in the time axis and time window accuracy, and $i v$ ) the long-term stability test. Useful insights on the signal shortterm and long-term stability can be found in Rial et al. [36], where three different ground-coupled antennas tuned to frequencies of investigation of $500 \mathrm{MHz}, 800 \mathrm{MHz}$ and $1000 \mathrm{MHz}$ have been used.

To the best of the authors' knowledge, no in-depth study is provided in the literature about the analysis of the compliance with the SNR test of a GPR signal, which conversely appears to be one of the main requirements by the manufacturers. The ASTM Standard suggests to "position the antenna at its far field distance approximately equal to maximum dimension of antenna 
aperture above a square metal plate with a width of antenna aperture, minimum" [24]. After turning on and warming-up the GPR unit for a 20-min time period, the test indicates the record of 100 waveforms, and the evaluation of the recorded waveform for signal-to-noise ratio. The following equation describes the signal-to-noise ratio according to the ASTM Standards:

$\operatorname{SNR}=\frac{\text { Signal Level }\left(A_{\mathrm{S}}\right)}{\text { Noise Level }\left(A_{n}\right)}$

where the noise voltage $\left(A_{n}\right)$ is defined as the maximum amplitude occurring between the metal plate reflection and the region up to the $50 \%$ of the time window after the metal plate reflection, and the signal level $\left(A_{s}\right)$ is defined as the amplitude of the echo from the metal plate. The Standard recommends to perform the SNR test on each of the above 100 waveforms and to take the average signal-to-noise value of the 100 waveforms as reference "signal-to-noise of the system". The Standard recommends the signal-to-noise ratio test results for the GPR unit to be greater than or equal to 20 (i.e., $+26 \mathrm{~dB}=20 \cdot \log _{10}(20)$, where the $\mathrm{dB}$ factors are computed for the power of the signals which are given in voltages into $1 \mathrm{ohm}$ standard resistances).

In this paper, the SNR test defined by the Standard D $6087-08$ ASTM [24] is taken as reference parameter for assessing the performance of the GPR signals. In particular, relationships between thresholds of SNR, relevant signal stability and central frequency of investigation are here discussed. Regardless of the specificity of this test, it is anyhow worth to mention how the methodology proposed in this study also applies to the other parameters discussed within the aforementioned ASTM document.

\section{SIGNAL PROCESSING METHODOLOGY FOR ASTM STANDARD}

The SNR test method, as defined by the D 6087 - 08 ASTM Standard [24], is here taken as the reference parameter for assessing the performance of the GPR signals, in terms of bias and variance. It is worthy to note that, to the best of our knowledge, there are no papers discussing the implications of bias and variance for assessing the performances of GPR systems, according to the ASTM Standards. Only three papers investigating on the precision of the GPR measurements 
have been found in the literature. In [57], the authors carry out a series of studies to identify the precision and accuracy wherewith GPR travel-times, velocities and interval properties can be estimated under controlled conditions. In addition, the work in [58] presents the results of various experiments for the analysis and calibration of 500, 800 and $1000 \mathrm{MHz}$ GPR shielded antennas. Finally, [59] discusses the precision attainable with GPR systems for quantitative subsurface target depth measurements, which is limited to the range uncertainty associated with the time sampling interval. Nevertheless, none of these papers provides any discussion about the precision of the SNR test method, especially in terms of bias. It is well-known that bias is related to consistency, in the sense that an estimator is consistent if convergent and unbiased (i.e. if it tends to the true value). The ASTM society defines bias as "a measure of the closeness to the truth" [23]. Hence, bias stands for the average difference to be expected between the estimator and the underlying parameter. Thereby, the estimator can additionally be expected to differ from the parameter due to the randomness in the sample. The mean square error (MSE), defined as the sum of the squared bias and the variance, is a measure used to try to reflect both types of difference. In the Results' Section, we have verified that the (squared) bias of the presented estimator is always less than its variance (i.e. the bias is negligible). In the following subsections, we first provide relationships between thresholds of SNR, relevant signal stability and central frequency of investigation. Afterwards, we provide such a discussion in Section 3.2, evaluating the bias and variance of the testing variable under consideration.

\subsection{Optimal threshold tuning}

As discussed in the previous Section and according to [24], the SNR of the GPR equipment on a linear scale should be equal or greater than 20 (i.e. equal or greater than $26 \mathrm{~dB}$, on a logarithmic scale). Nevertheless, no further information is provided on how the threshold has been set, nor to which accuracy (or signal stability) of the GPR equipment this threshold corresponds. In this paper, we provide the signal processing methodology to evaluate the proper threshold for the specific GPR equipment, according to a fixed desired (i.e. target) level of accuracy. 
First of all, we evaluate the SNR of the system as the average SNR over a number of $L$ trials as follows:

$$
S N R=\frac{1}{L} \cdot \sum_{j=1}^{L} S N R_{j},
$$

In particular, $S N R_{j}$ is the SNR of the $j$-th experiment, and defined as the ratio between the mean signal and the noise peaks, respectively. In more details, $S N R_{j}$ is evaluated according to the following:

$$
S N R_{j}=\frac{\text { Mean Signal Level }\left(\hat{A}_{\mathrm{s}, \mathrm{j}}\right)}{\text { Mean Noise Level }\left(\widehat{A}_{\mathrm{n}, \mathrm{j}}\right)}
$$

where $\hat{A}_{\mathrm{s}, \mathrm{j}}$ is the mean amplitude (averaged over $K$ radar waveforms) of the signal level (i.e. of the echo from the metal plate), i.e.:

$$
\hat{A}_{\mathrm{s}, j}=\frac{1}{K} \sum_{i=1}^{K}\left(A_{\mathrm{s}, j, i}\right)
$$

and $A_{\mathrm{s}, j, i}$ is the maximum signal level of the $i$-th waveform for the $j$-th experiment. Similarly, $\hat{A}_{\mathrm{n}, \mathrm{j}}$ is the mean (averaged over $K$ radar waveforms) maximum amplitude occurring between the metal plate reflection and the region up to the $50 \%$ of the time window after the metal plate reflection (i.e. the mean noise level), i.e.:

$$
\hat{A}_{\mathrm{n}, j}=\frac{1}{K} \sum_{i=1}^{K}\left(A_{\mathrm{n}, j, i}\right)
$$

where $A_{\mathrm{n}, j, i}$ is the maximum noise level of the $i$-th waveform for the $j$-th experiment

Then, the SNR in (4) should be compared with a proper pre-selected threshold $\gamma$, and if SNR $>\gamma$, the test regarding the GPR signal stability is passed [24]. Since all the terms of the sum in (4) represent SNRs of different experiments, they also represent physically independent and hence statistically independent random variables. Accordingly, the testing variable in (4) is asymptotically $(L \rightarrow \infty)$ Gaussian as a direct consequence of the central limit theorem [60]. Then, let us now define with $P_{A C C}$ the desired (or target) level of accuracy (in percentage) requested to the GPR system. Hence, by following the same approach used in conventional statistical testing methods (see for example [61 - 63]), the threshold can be asymptotically tuned from a straightforward evaluation of the Gaussian integral for a fixed level of $P_{A C C}$ using the following: 


$$
\gamma=E[S N R]+(2 \cdot \operatorname{var}[S N R])^{1 / 2} \cdot \operatorname{erf}^{-1}\left(1-2 \cdot P_{A C C}\right)
$$

where $E[S N R]$ and $\operatorname{var}[S N R]$ state respectively for the mean and variance of the testing variable in (4), and $\operatorname{erf}^{I}()$ is the inverse of the well-known Gaussian error function defined as:

$$
\operatorname{erf}(x)=\frac{2}{\sqrt{\pi}} \int_{0}^{x} e^{-t^{2}} d t
$$

Equivalently, if we are interested to know (given a proper threshold) to which $P_{A C C}$ that threshold corresponds to, we can exploit the following equation:

$$
P_{A C C}=\frac{1}{2}+\frac{1}{2} \cdot \operatorname{erf}\left[(-\gamma+E[S N R]) \cdot(2 \cdot \operatorname{var}[S N R])^{-1 / 2}\right]
$$

\subsection{Performance evaluation}

In this Section, it is evaluated the performance of the SNR test method, by theoretically assessing the bias and the variance of the estimation error of the testing variable in (4). It has to be noted that the testing variable is obtained as the sum of $L$ statistically independent variables. Both the bias and variance of the estimation error can be assessed as the sum of the biases and variances of these $L$ independent variables, as:

$$
E[\widehat{\mathrm{SNR}}]=\frac{1}{L} \cdot \sum_{j=1}^{L} E\left[\widehat{\mathrm{SRR}}_{j}\right], \quad \operatorname{var}[\widehat{\mathrm{SNR}}]=\frac{1}{L} \cdot \sum_{j=1}^{L} \operatorname{var}\left[\widehat{\mathrm{SRR}}_{j}\right]
$$

where $\widehat{S N R}=S N R-E[S N R]$ is the estimation error. In the following analysis, we first evaluate the bias and the variance of $\widehat{\mathrm{NR}}_{j}$, and then we compute the bias and variance in (11). Let us now define, for the sake of the compactness and following the same approach as in [61, 62]: $\varepsilon_{\mathrm{s}, \mathrm{j}}=\hat{A}_{\mathrm{s}, \mathrm{j}}-E\left[\hat{A}_{\mathrm{s}, \mathrm{j}}\right], \varepsilon_{\mathrm{n}, \mathrm{j}}=\hat{A}_{\mathrm{n}, \mathrm{j}}-E\left[\hat{A}_{\mathrm{n}, \mathrm{j}}\right]$ as the signal and noise amplitude estimation's errors, which are assumed to be zero-mean random variables. Under the assumption of small errors (i.e. low variability) for $\left(\hat{A}_{\mathrm{s}, \mathrm{j}}, \hat{A}_{\mathrm{n}, \mathrm{j}}\right)$, the estimation errors can be accordingly evaluated by a twodimensional reduced Taylor expansion up to the $2^{\text {nd }}$ order [63]:

$$
\begin{aligned}
& E\left[\widehat{\mathrm{SNR}}_{j}\right]=\left.\frac{1}{2} \frac{\partial^{2} \widehat{\mathrm{SNR}}_{j}}{\partial \hat{A}_{s, j}^{2}}\right|_{\varepsilon_{S, j}=\varepsilon_{n, j}=0} \cdot E\left[\varepsilon_{s, j}^{2}\right]+\left.\frac{1}{2} \frac{\partial^{2} \widehat{\mathrm{SNR}}_{j}}{\partial \widehat{A}_{n, j}^{2}}\right|_{\varepsilon_{S, j}=\varepsilon_{n, j}=0} \cdot E\left[\varepsilon_{n, j}^{2}\right]+ \\
& \frac{1}{2} \frac{\partial \widehat{\mathrm{SNR}}_{j}}{\left.\partial \widehat{A}_{s, j} \partial \widehat{A}_{n, j}\right|_{S_{s, j}=\varepsilon_{n, j}=0}} \mid \cdot E\left[\varepsilon_{S} \varepsilon_{n}\right]
\end{aligned}
$$




$$
\operatorname{var}\left[\widehat{\mathrm{SNR}}_{j}\right]=\left.\left(\frac{\partial \widehat{\mathrm{SNR}}_{j}}{\partial \widehat{A}_{\mathrm{S}, \mathrm{j}}}\right)^{2}\right|_{\varepsilon_{s, j}=\varepsilon_{n, j}=0} \cdot E\left[\varepsilon_{s, j}^{2}\right]+\left.\left(\frac{\partial \widehat{\mathrm{SNR}}_{j}}{\partial \widehat{A}_{\mathrm{n}, \mathrm{j}}}\right)^{2}\right|_{\varepsilon_{s, j}=\varepsilon_{n, j}=0} \cdot E\left[\varepsilon_{n, j}^{2}\right]+
$$

$\left.\left.\frac{\partial \widehat{\mathrm{SNR}}_{j}}{\partial \widehat{A}_{\mathrm{s}, \mathrm{j}}}\right|_{\mathcal{E}_{s, j}=\varepsilon_{n, j}=0} \cdot \frac{\partial \widehat{\mathrm{SNR}}_{j}}{\partial \hat{A}_{\mathrm{n}, \mathrm{j}}}\right|_{\varepsilon_{S, j}=\varepsilon_{n, j}=0} \cdot E\left[\varepsilon_{s, j} \varepsilon_{n, j}\right]$

The assumption of small errors for $\left(\hat{A}_{\mathrm{s}, \mathrm{j}}, \hat{A}_{\mathrm{n}, \mathrm{j}}\right)$ will be empirically verified and confirmed by laboratory experiments in the Results' Section. The algebraic expressions (12) and (13) are trivially derived from a computation of the partial derivatives of the expressions in (4). In particular, the partial derivatives in (12) and (13) are given by:

$$
\begin{aligned}
& \frac{\partial^{2} \widehat{\mathrm{SNR}}_{j}}{\partial \hat{A}_{s, j}^{2}}=0 ; \\
& \frac{\partial^{2} \widehat{\mathrm{SNR}}_{j}}{\partial \hat{A}_{n, j}^{2}}=\left[\frac{2 \cdot \widehat{A}_{\mathrm{s}, \mathrm{j}}}{\left(\hat{A}_{\mathrm{n}, \mathrm{j}}\right)^{3}}\right] ; \\
& \frac{\partial \widehat{\mathrm{SNR}}_{j}}{\partial \widehat{A}_{\mathrm{s}, \mathrm{j}} \hat{A}_{\mathrm{n}, \mathrm{j}}}=-\frac{1}{\left(\widehat{A}_{\mathrm{n}, \mathrm{j}}\right)^{2}} \\
& \frac{\partial \widehat{\mathrm{SNR}}_{j}}{\partial \hat{A}_{\mathrm{s}, \mathrm{j}}}=\frac{1}{\hat{A}_{\mathrm{n}, \mathrm{j}}} ; \\
& \frac{\partial \widehat{\mathrm{SNR}}_{j}}{\partial \hat{A}_{\mathrm{n}, \mathrm{j}}}=-\frac{\hat{A}_{\mathrm{S}, \mathrm{j}}}{\left(\widehat{A}_{\mathrm{n}, \mathrm{j}}\right)^{2}}
\end{aligned}
$$

The variance $E\left[\varepsilon_{\mathrm{s}, \mathrm{j}}^{2}\right]$ can be derived as:

$$
\begin{gathered}
E\left[\varepsilon_{\mathrm{s}, \mathrm{j}}^{2}\right]=\operatorname{var}\left(\hat{A}_{\mathrm{s}, j}\right)=\mathrm{E}\left[\hat{A}_{\mathrm{s}, j} \hat{A}_{\mathrm{s}, j}\right]-\mathrm{E}^{2}\left[\hat{A}_{\mathrm{s}, j}\right]=\mathrm{E}\left[\frac{1}{K} \sum_{i=1}^{K}\left(A_{\mathrm{s}, j, i}\right)^{2} \frac{1}{K} \sum_{m=1}^{K}\left(A_{\mathrm{s}, j, m}\right)^{2}\right]- \\
{\left[\frac{1}{K} \sum_{i=1}^{K}\left(A_{\mathrm{s}, j, i}\right)\right]^{2}=\cdots=\frac{1}{K}\left\{\frac{1}{K} \sum_{i=1}^{K}\left(A_{\mathrm{s}, j, i}\right)^{2}-\left[\frac{1}{K} \sum_{i=1}^{K}\left(A_{\mathrm{s}, j, i}\right)\right]^{2}\right\}}
\end{gathered}
$$

Following the same approach, $E\left[\varepsilon_{\mathrm{n}, j}^{2}\right]$ is given by:

$$
E\left[\varepsilon_{\mathrm{n}, j}^{2}\right]=\operatorname{var}\left(\hat{A}_{\mathrm{n}, j}\right)=\cdots=\frac{1}{K}\left\{\frac{1}{K} \sum_{i=1}^{K}\left(A_{\mathrm{n}, j, i}\right)^{2}-\left[\frac{1}{K} \sum_{i=1}^{K}\left(\mathrm{~A}_{\mathrm{n}, j, i}\right)\right]^{2}\right\}
$$

Finally, the expression of $E\left[\varepsilon_{\mathrm{s}, j} \varepsilon_{\mathrm{n}, j}\right]$, i.e. the covariance (cov) between $\varepsilon_{\mathrm{s}, j}$ and $\varepsilon_{\mathrm{n}, j}$, can be determined as follows:

$$
E\left[\varepsilon_{\mathrm{s}, j} \varepsilon_{\mathrm{n}, j}\right]=\operatorname{cov}\left(\hat{A}_{\mathrm{s}, j} \hat{A}_{\mathrm{n}, j}\right)=\frac{1}{K}\left\{\frac{1}{K} \sum_{i=1}^{K}\left(A_{\mathrm{s}, j, i} \mathrm{~A}_{\mathrm{n}, j, i}\right)-\frac{1}{K} \sum_{i=1}^{K}\left(\mathrm{~A}_{\mathrm{s}, j, i}\right) \frac{1}{K} \sum_{i=1}^{K}\left(\mathrm{~A}_{\mathrm{n}, j, i}\right)\right\}
$$


Then, by substituting each of the expressions (14)-(21) into (12) and (13) and then into (4), the desired expressions of the estimation errors can be calculated as follows:

$$
\begin{gathered}
E[\widehat{\mathrm{SNR}}]=\frac{1}{L} \cdot \sum_{j=1}^{L} \frac{1}{\left(\hat{A}_{\mathrm{n}, \mathrm{j}}\right)^{2}} \cdot\left\{\frac{\hat{A}_{\mathrm{s}, \mathrm{j}}}{\widehat{A}_{\mathrm{n}, \mathrm{j}}} \cdot E\left[\varepsilon_{\mathrm{n}, j}^{2}\right]-\frac{1}{2} \cdot E\left[\varepsilon_{\mathrm{s}, j} \varepsilon_{\mathrm{n}, j}\right]\right\}= \\
=\frac{1}{L} \cdot \sum_{j=1}^{L} \frac{1}{K^{2} \cdot\left(\widehat{A}_{\mathrm{n}, \mathrm{j}}\right)^{2}} \cdot\left\{\frac{\hat{A}_{\mathrm{s}, \mathrm{j}}}{\widehat{A}_{\mathrm{n}, \mathrm{j}}} \cdot\left[\sum_{i=1}^{K}\left(A_{\mathrm{n}, \mathrm{j}, i}\right)^{2}-\frac{1}{K}\left[\sum_{i=1}^{K}\left(\mathrm{~A}_{\mathrm{n}, \mathrm{j}, i}\right)\right]^{2}\right]-\frac{1}{2} \cdot\left[\sum_{i=1}^{K}\left(\mathrm{~A}_{\mathrm{s}, \mathrm{j}, i} \mathrm{~A}_{\mathrm{n}, i}\right)-\right.\right. \\
\left.\left.\frac{1}{K} \sum_{i=1}^{K}\left(\mathrm{~A}_{\mathrm{s}, \mathrm{j}, i}\right) \cdot \sum_{i=1}^{K}\left(\mathrm{~A}_{\mathrm{n}, \mathrm{j}, i}\right)\right]\right\} \\
\quad \operatorname{var}[\mathrm{SNR}]=\frac{1}{L} \cdot \sum_{j=1}^{L} \frac{1}{\left(\widehat{A}_{\mathrm{n}, \mathrm{j}}\right)^{2}} \cdot\left\{E\left[\varepsilon_{\mathrm{s}, \mathrm{j}}^{2}\right]+\left(\frac{\widehat{A}_{\mathrm{s}, \mathrm{j}}}{\widehat{A}_{\mathrm{n}, \mathrm{j}}}\right)^{2} \cdot E\left[\varepsilon_{\mathrm{n}, j}^{2}\right]-\frac{\widehat{A}_{\mathrm{s}, \mathrm{j}}}{\widehat{A}_{\mathrm{n}, \mathrm{j}}} \cdot\left[\varepsilon_{\mathrm{s}, j} \varepsilon_{\mathrm{n}, j}\right]\right\}= \\
\left.\frac{1}{K}\left[\sum_{i=1}^{K}\left(\mathrm{~A}_{\mathrm{n}, \mathrm{j}, i}\right)\right]^{2}\right]-\frac{1}{K^{2} \cdot\left(\hat{A}_{\mathrm{n}, \mathrm{j}}\right)^{2}} \cdot\left\{\left[\sum_{i=1}^{K}\left(A_{\mathrm{s}, \mathrm{j}, i}\right)^{2}-\frac{1}{K} \cdot\left[\sum_{i=1}^{K}\left(\mathrm{~A}_{\mathrm{s}, \mathrm{j}, i}\right)\right]^{2}\right]+\left(\frac{\hat{A}_{\mathrm{s}, \mathrm{j}}}{\widehat{A}_{\mathrm{n}, \mathrm{j}}}\right)^{2} \cdot\left[\sum_{i=1}^{K}\left(\mathrm{~A}_{\mathrm{s}, \mathrm{j}, i} \mathrm{~A}_{\mathrm{n}, \mathrm{j}, i}\right)-\frac{1}{K} \sum_{i=1}^{K}\left(\mathrm{~A}_{\mathrm{n}, \mathrm{j}, i}\right)^{2}-\right.\right.
\end{gathered}
$$

It has to be noted that both the estimations in (22) and (23) vary with $1 / K$, meaning that the SNR estimator is consistent (i.e. as the number of considered radar waveforms $K$ becomes larger and larger, the estimate tends to the true value).

\section{NUMERICAL RESULTS}

\subsection{Laboratory set-up}

Several laboratory-scale tests were performed according to the set-up shown in Fig. 2. In more details, the antenna under test was hung from a pairs of wooden bars, and placed at different heights from the ground in the range of $40 \mathrm{~cm}$, included, i.e., a distance usually recommended by GPR manufacturers for air-launched GPR set-ups. Signal responses at heights of $30 \mathrm{~cm}, 40 \mathrm{~cm}$, and $50 \mathrm{~cm}$ were therefore collected to analyze the impact on the signal accuracy (or stability) of the variation of the antenna heights. This may be mostly due to the deflections induced to the surveying apparatus by the combination of remarkable traffic speeds and damaged conditions of 
the pavement surface when performing GPR measurements in real roads. Considerations on the signal response in near-field and far-field conditions can also be drawn.

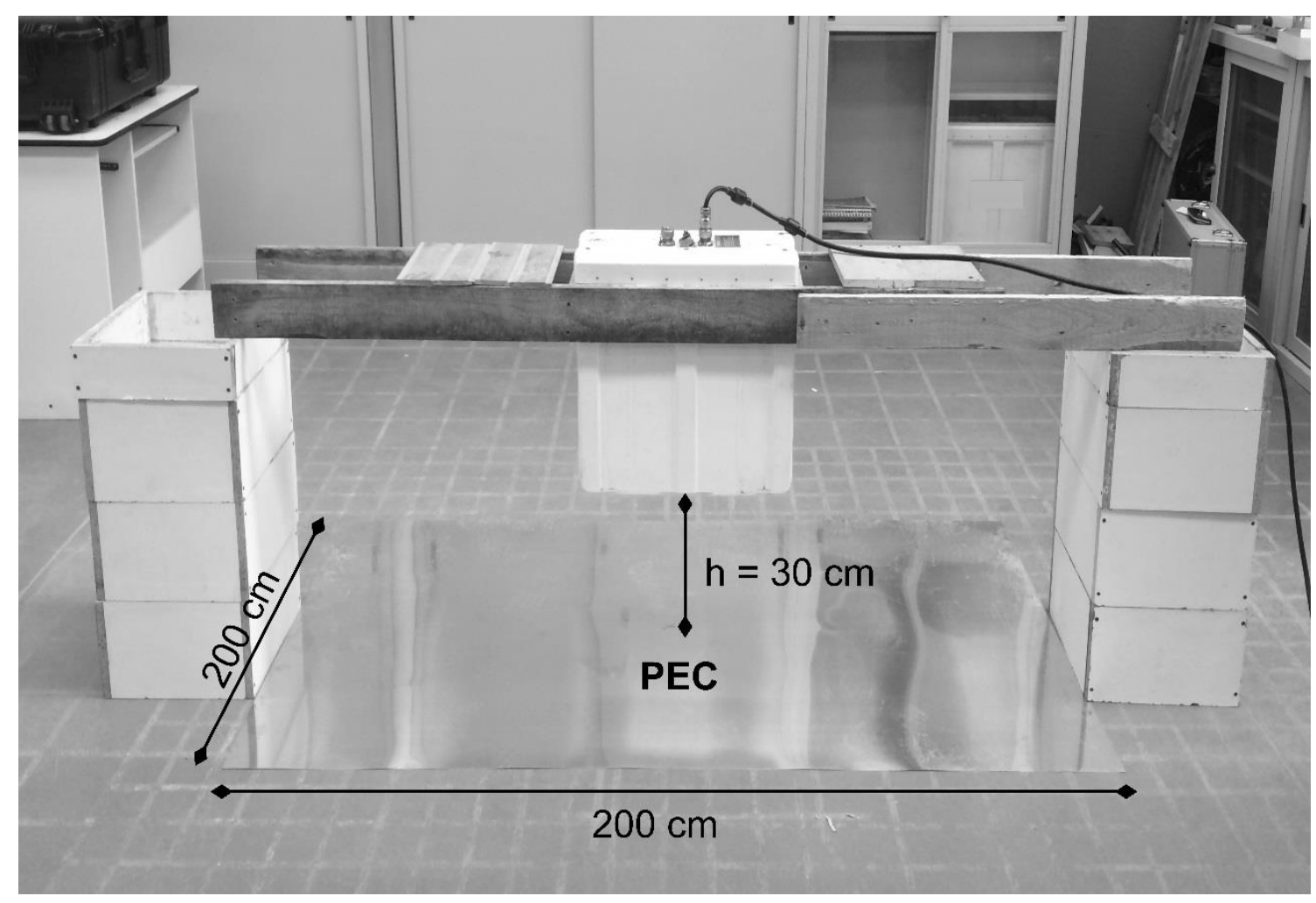

Fig. 2. Laboratory-scale set-up for the investigation at $30 \mathrm{~cm}$ of height between the bottom of the radar box and the PEC surface.

The floor under the antennas was covered by a $200 \mathrm{~cm} \times 200 \mathrm{~cm}$ copper sheet acting as perfect electric conductor (PEC), and capable to completely reflect the propagation waves and generating a pulse with maximum amplitude.

Measurements at each of the aforementioned heights were performed using three air-coupled GPR systems with different central frequencies of 1 and $2 \mathrm{GHz}$. As for this latter frequency, one $2 \mathrm{GHz}$ central frequency antenna designed for the European market (from now on, referred to as "2 GHz EU") and one $2 \mathrm{GHz}$ central frequency low-powered antenna for the North American market (from now on, referred to as "2 GHz NA") were employed. Such frequencies were selected for their widespread use in pavement engineering applications wherein they can provide high- 
resolution and fast imaging of the shallow layers of pavements. Data were acquired within time windows of $25 \mathrm{~ns}$ and $15 \mathrm{~ns}$, and time steps of $4.88 \times 10^{-2} \mathrm{~ns}$ and $2.93 \times 10^{-2} \mathrm{~ns}$ for, respectively, the $1 \mathrm{GHz}$ and the $2 \mathrm{GHz}$ systems. The representativeness of the signal collected in laboratory environment was proved by the negligible differences found in the signals gathered within an outdoor test site. To provide statistically-significant data, each combination of "height" and "central frequency" was collected with 100 trials containing 100 GPR traces each.

\subsection{Experimental outcomes}

The assumptions made in the previous Section have been firstly empirically verified. In particular, the variability of both the signal and noise peaks, for 100 consecutive radar traces, at different heights and several frequencies of the GPR equipment, has been evaluated. Fig. 3 (a) and Fig. 3 (b) show the normalized (to 1) amplitude variations of the signal peak $\left(A_{s}\right)$ and the noise peak $\left(A_{n}\right)$, respectively, after the PEC reflection using the $1 \mathrm{GHz}$ GPR system. It can be noted from the figures that the maximum variation of the signal peak is within the $4 \%$, at an antenna's height of $\mathrm{h}=50 \mathrm{~cm}$. The same behavior occurs with the noise peak, as shown in Fig. 3 (b).
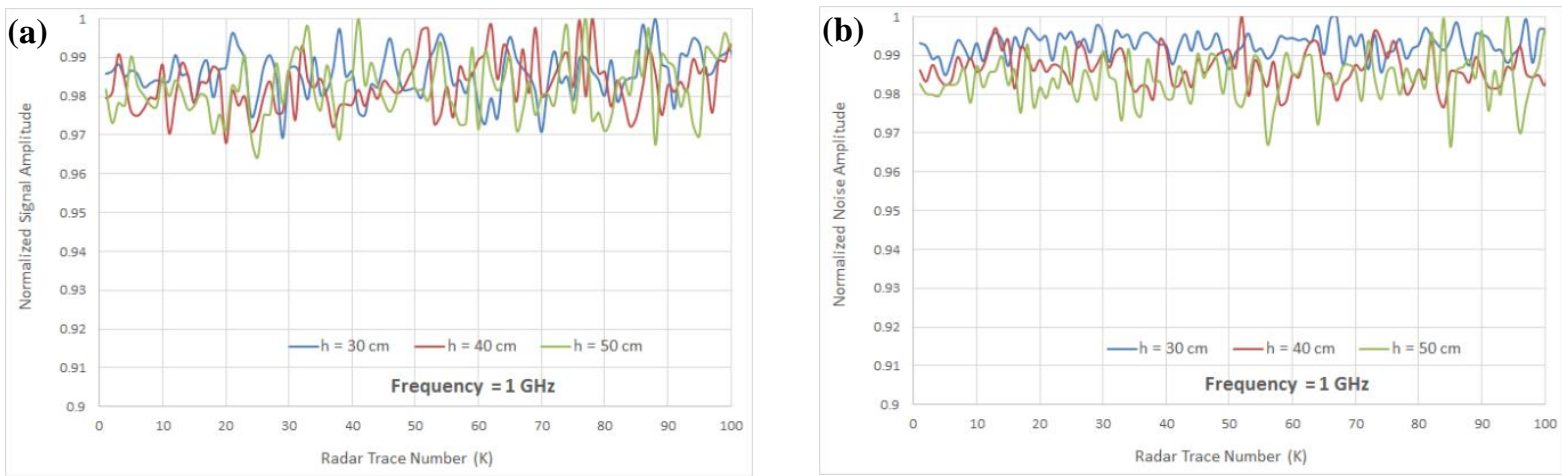

Fig. 3. Normalized (to 1) amplitude variations for 100 consecutive radar traces of: (a) the signal peak $\left(A_{s}\right)$, and (b) the noise peak $\left(A_{n}\right)$ after PEC reflection, with the $1 \mathrm{GHz}$ GPR system. 
Analogously, we have verified that this assumption of low variability is still valid also for GPR systems with different antennas. In more details, Fig. 4 (a, b) and Fig. 5 (a, b) illustrate the case of signal and noise variability for the $2 \mathrm{GHz}$ EU and $2 \mathrm{GHz}$ NA systems, respectively. As in the previous case, we can notice a maximum variation of the signal and noise peak within the $6 \%$ for the $2 \mathrm{GHZ}$ EU equipment, whereas this value is between the $6-7 \%$ in the case of the $2 \mathrm{GHz} \mathrm{NA}$ system.
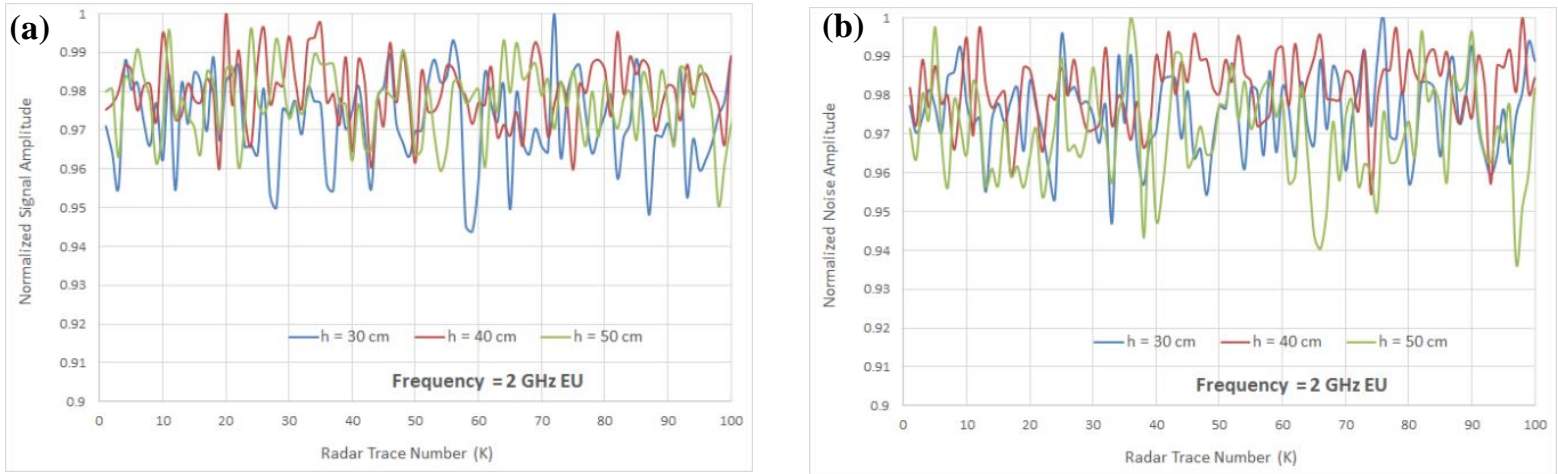

Fig. 4. Normalized (to 1) amplitude variations for 100 consecutive radar traces of: (a) the signal peak $\left(A_{s}\right)$, and (b) the noise peak $\left(A_{n}\right)$ after PEC reflection, with the $2 \mathrm{GHz}$ EU GPR system.

(a)

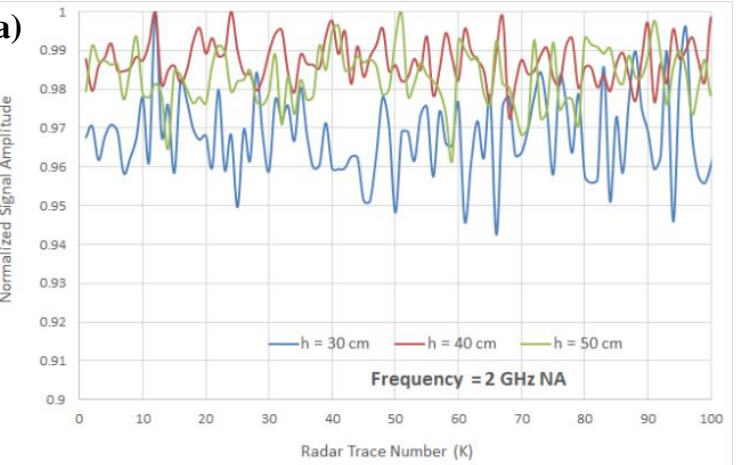

(b)

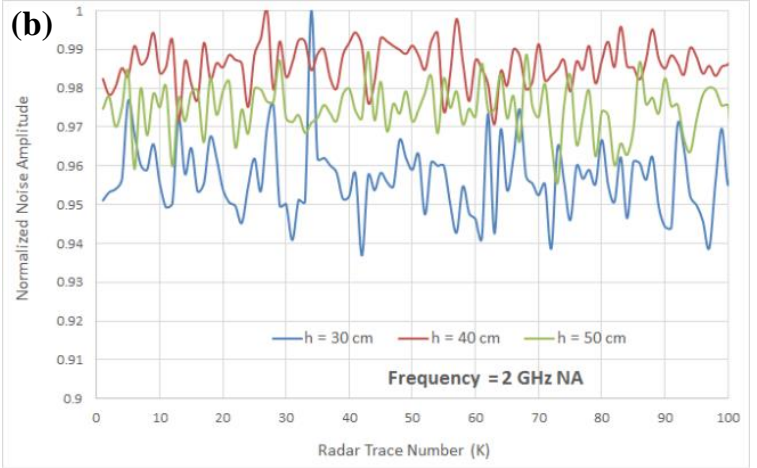

Fig. 5. Normalized (to 1) amplitude variations for 100 consecutive radar traces of: (a) the signal peak $\left(A_{s}\right)$, and (b) the noise peak $\left(A_{n}\right)$ after PEC reflection, with the 2GHz NA GPR system.

In addition, we have evaluated the variances of the signal and noise variations in all the considered cases and reported the results in Table I and Table II, respectively. Again, such results confirm the validity of the assumption of small errors for the signal and noise peaks. 
Tab. I. Variances of the signal peak for 100 consecutive radar traces

\begin{tabular}{|c|c|c|c|}
\hline $\begin{array}{c}\text { Freq. of the GPR } \\
\text { System }\end{array}$ & $\mathbf{h}=\mathbf{3 0} \mathbf{~ c m}$ & $\mathbf{h}=\mathbf{4 0} \mathbf{~ c m}$ & $\mathbf{h}=\mathbf{5 0} \mathbf{~ c m}$ \\
\hline $\mathbf{1 ~ G H z}$ & $\approx 3.46 \cdot 10^{-5}$ & $\approx 4.53 \cdot 10^{-5}$ & $\approx 6.11 \cdot 10^{-5}$ \\
\hline $\mathbf{2}$ GHZ EU & $\approx 1.29 \cdot 10^{-4}$ & $\approx 7.36 \cdot 10^{-5}$ & $\approx 8.04 \cdot 10^{-5}$ \\
\hline $\mathbf{2}$ GHZ NA & $\approx 1.17 \cdot 10^{-4}$ & $\approx 3.03 \cdot 10^{-5}$ & $\approx 5.29 \cdot 10^{-5}$ \\
\hline
\end{tabular}

Tab. II. Variances of the noise peak for 100 consecutive radar traces

\begin{tabular}{|c|c|c|c|}
\hline $\begin{array}{c}\text { Freq. of the GPR } \\
\text { System }\end{array}$ & $\mathbf{h}=\mathbf{3 0} \mathbf{~ c m}$ & $\mathbf{h}=\mathbf{4 0} \mathbf{~ c m}$ & $\mathbf{h}=\mathbf{5 0} \mathbf{~ c m}$ \\
\hline $\mathbf{1 ~ G H z}$ & $\approx 1.02 \cdot 10^{-5}$ & $\approx 2.11 \cdot 10^{-5}$ & $\approx 3.71 \cdot 10^{-5}$ \\
\hline $\mathbf{2}$ GHZ EU & $\approx 1.08 \cdot 10^{-4}$ & $\approx 8.04 \cdot 10^{-5}$ & $\approx 1.64 \cdot 10^{-4}$ \\
\hline $\mathbf{2}$ GHZ NA & $\approx 9.16 \cdot 10^{-5}$ & $\approx 2.98 \cdot 10^{-5}$ & $\approx 4.37 \cdot 10^{-5}$ \\
\hline
\end{tabular}

Hence, we can now evaluate the performance of the SNR test method, by computing the bias and variance of the estimation errors, according to (21) and (22). In particular, Fig. 6 (a, b) report the mean and bias of the estimation error for a $1 \mathrm{GHz}$ GPR equipment, and several antennas' heights versus the number $K$ of analyzed radar traces. It is worth nothing that both the bias and variance of the estimation error decrease, whereas the value of $K$ increases. Fig. 7 (a, b) and Fig. 8 (a, b) illustrate the cases of both the $2 \mathrm{GHz}$ EU and $2 \mathrm{GHz}$ NA GPR systems, respectively.
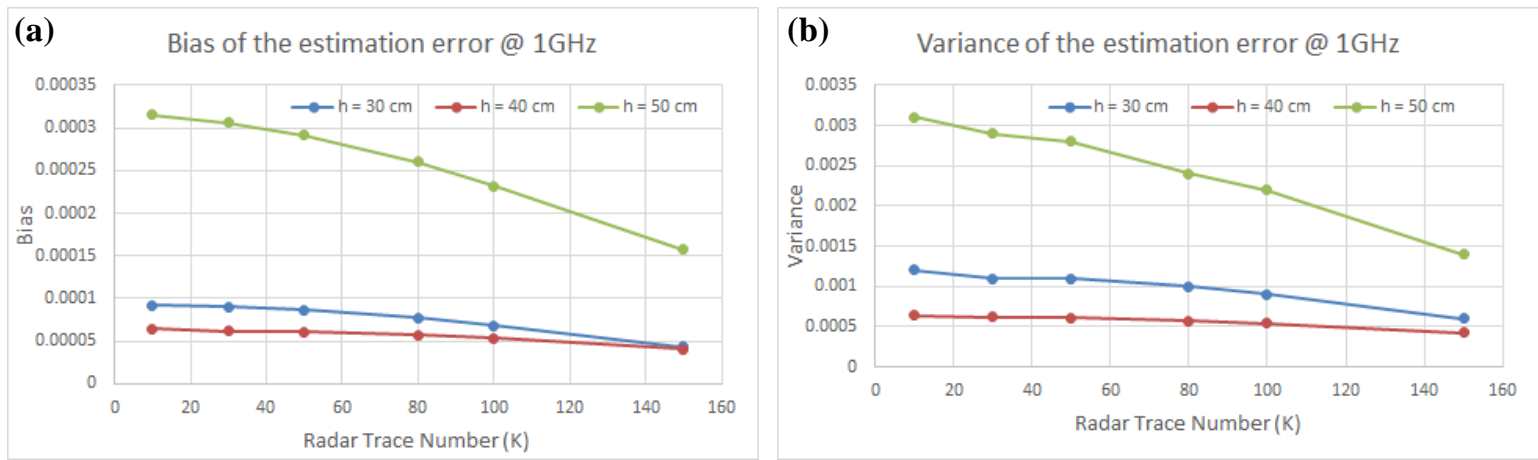

Fig. 6. (a) Bias and (b) Variance of the estimation error for a GPR with a central frequency of $1 \mathrm{GHz}$, and three different heights $(30,40$, and $50 \mathrm{~cm})$ from the metal plate. 

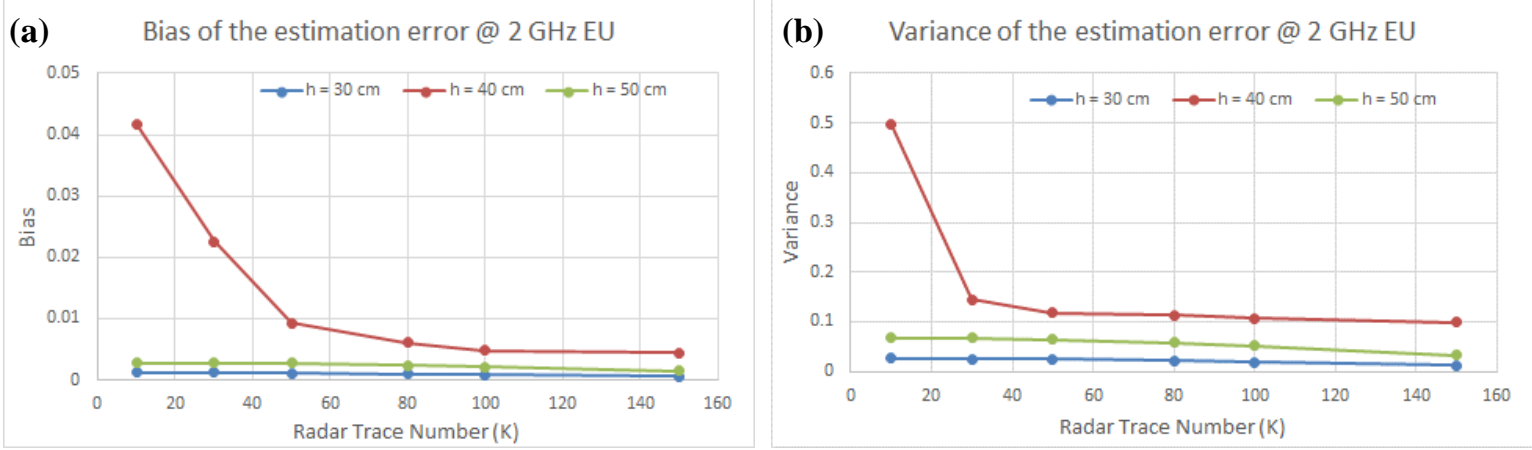

Fig. 7. (a) Bias and (b) Variance of the estimation error for a GPR with a central frequency of $2 \mathrm{GHz} \mathrm{EU}$, and three different heights $(30,40$, and $50 \mathrm{~cm})$ from the metal plate.
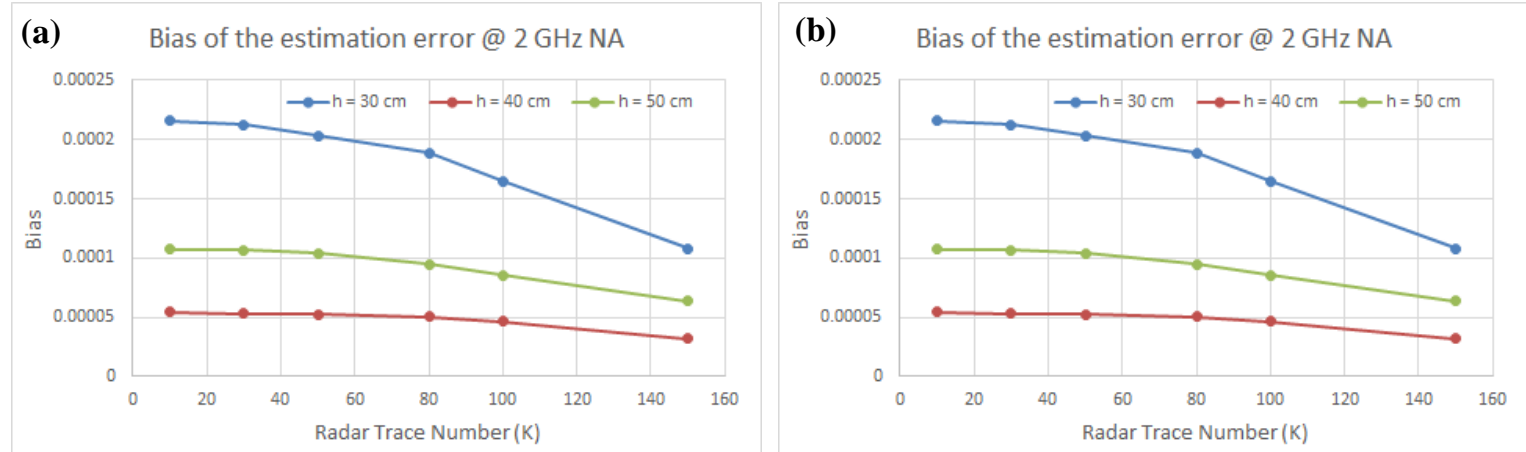

Fig. 8. (a) Bias and (b) Variance of the estimation error for a GPR with a central frequency of $2 \mathrm{GHz} \mathrm{NA}$, and three different heights $(30,40$, and $50 \mathrm{~cm})$ from the metal plate.

It is worth noting that in all the previous cases considered, we have verified that the bias of the presented estimator is negligible, i.e. (bias) ${ }^{2}<<$ var. It must also be noted that the SNR estimator is always an asymptotically consistent estimator for all the cases of interest. Finally, we have also evaluated the $95 \%$ confidence interval of the mean and bias estimates, as shown in Tab. III and Tab. IV, respectively. Their confidence intervals are provided to illustrate the accuracy of the estimates at different heights (i.e. 30,40 , and $50 \mathrm{~cm}$ ) and for the three GPR systems under investigation (i.e. $1 \mathrm{GHz}, 2 \mathrm{GHz} \mathrm{EU}$, and $2 \mathrm{GHz} \mathrm{NA}$ ).

\begin{tabular}{|c|c|c|c|}
\hline $\begin{array}{c}\text { Frequency of the } \\
\text { GPR System }\end{array}$ & $h=30 \mathrm{~cm}$ & $\mathbf{h}=40 \mathrm{~cm}$ & $\mathbf{h}=50 \mathrm{~cm}$ \\
\hline
\end{tabular}




\begin{tabular}{|c|c|c|c|}
\hline 1 GHz & $\pm 5.66 \cdot 10^{-6}$ & $\pm 5.12 \cdot 10^{-6}$ & $\pm 1.76 \cdot 10^{-5}$ \\
\hline 2 GHZ EU & $\pm 6.89 \cdot 10^{-5}$ & $\pm 6.81 \cdot 10^{-4}$ & $\pm 1.69 \cdot 10^{-4}$ \\
\hline 2 GHZ NA & $\pm 1.4 \cdot 10^{-5}$ & $\pm 3.31 \cdot 10^{-6}$ & $\pm 7.81 \cdot 10^{-6}$ \\
\hline
\end{tabular}

Tab. III. Confidence interval (95\%) of the mean estimate for 100 consecutive radar traces.

Tab. IV. Confidence interval (95\%) of the variance estimate for 100 consecutive radar traces

\begin{tabular}{|c|c|c|c|}
\hline $\begin{array}{c}\text { Frequency of the } \\
\text { GPR System }\end{array}$ & $\mathbf{h}=\mathbf{3 0} \mathbf{~ c m}$ & $\mathbf{h}=\mathbf{4 0} \mathbf{~ c m}$ & $\mathbf{h}=\mathbf{5 0} \mathbf{~ c m}$ \\
\hline $\mathbf{1 ~ G H z}$ & $\pm 6.54 \cdot 10^{-5}$ & $\pm 2.23 \cdot 10^{-5}$ & $\pm 1.95 \cdot 10^{-4}$ \\
\hline $\mathbf{2}$ GHZ EU & $\pm 1.8 \cdot 10^{-5}$ & $\pm 5.2 \cdot 10^{-4}$ & $\pm 3.2 \cdot 10^{-5}$ \\
\hline $\mathbf{2}$ GHZ NA & $\pm 3.32 \cdot 10^{-5}$ & $\pm 8.2 \cdot 10^{-6}$ & $\pm 1.63 \cdot 10^{-5}$ \\
\hline
\end{tabular}

Finally, the dependence of the GPR signal accuracy (or signal stability) versus the value of the selected threshold has been evaluated. By exploiting (9), we can determine to which accuracy (expressed in percentage) corresponds the pre-selected threshold. Fig. 9 reports the case of the $1 \mathrm{GHz}$ equipment for the whole range of heights investigated. It can be seen how the accuracy of the GPR signal strongly depends on the pre-selected threshold value. As an example, if we aim at achieving an accuracy greater than $90 \%$ for a $1 \mathrm{GHz}$ GPR system, the optimal threshold should not be greater than $\approx 11 \mathrm{~dB}$ when $h=30 \mathrm{~cm}$. The threshold value modifies accordingly to $h$. Indeed, if $h=40 \mathrm{~cm}$, or $h=50 \mathrm{~cm}$, the threshold changes its value and should not be greater than $12.3 \mathrm{~dB}$ and $15.2 \mathrm{~dB}$, respectively. 


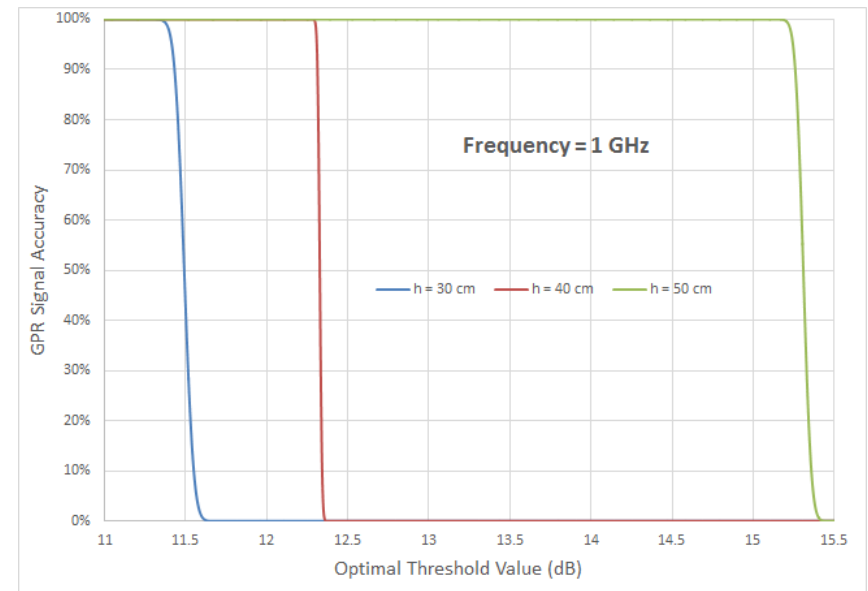

Fig. 9. Accuracy vs. optimal threshold for a GPR with a central frequency of $1 \mathrm{GHz}$ at three different heights $(30,40$, and $50 \mathrm{~cm})$ from the metal plate

It has to be noted that the optimal threshold is also a function of the central frequency of investigation. Figs. 10 and 11 show how the accuracy of the GPR signal varies versus the threshold in the cases of the 2GHZ EU and the 2GHZ NA GPR systems, respectively.

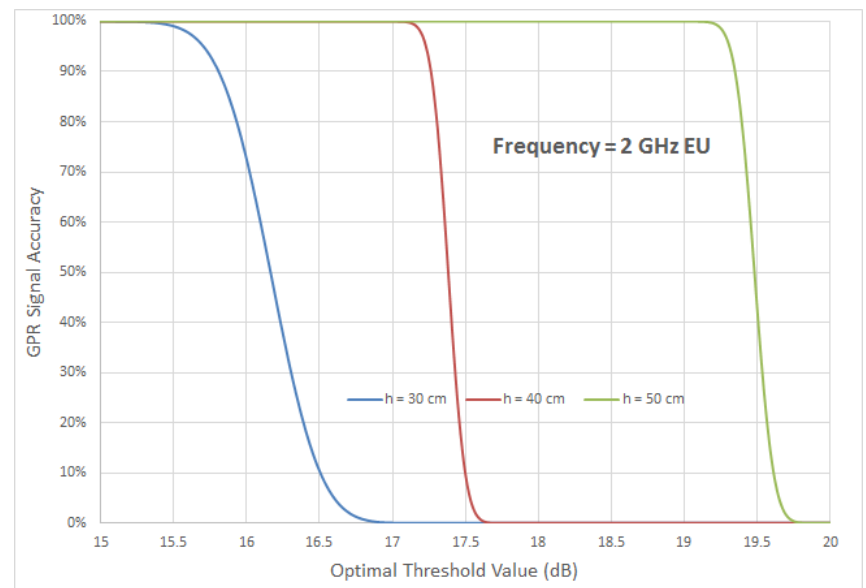

Fig. 10. Accuracy vs. optimal threshold for a GPR with a central frequency of $2 \mathrm{GHz} E \mathrm{EU}$ at three different heights $(30,40$, and $50 \mathrm{~cm})$ from the metal plate 


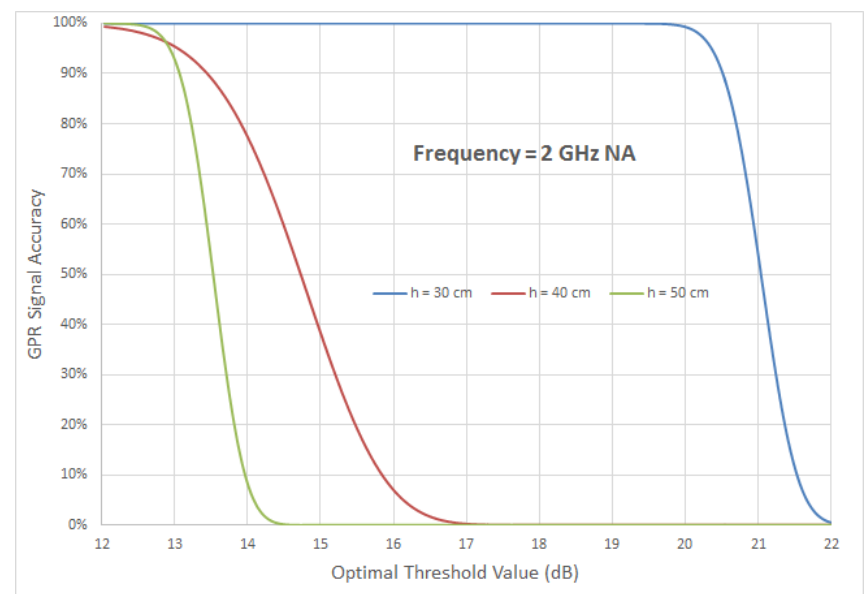

Fig. 11. Accuracy vs. optimal threshold for a GPR with a central frequency of $2 \mathrm{GHz}$ NA at three different heights $(30,40$, and $50 \mathrm{~cm})$ from the metal plate

It is worth noting that the value of the optimal threshold depends on both the frequency of investigation and the antenna's height (see Fig. 12). Indeed, we have to choose again different values of the threshold for different heights, as a function of the wanted accuracy.

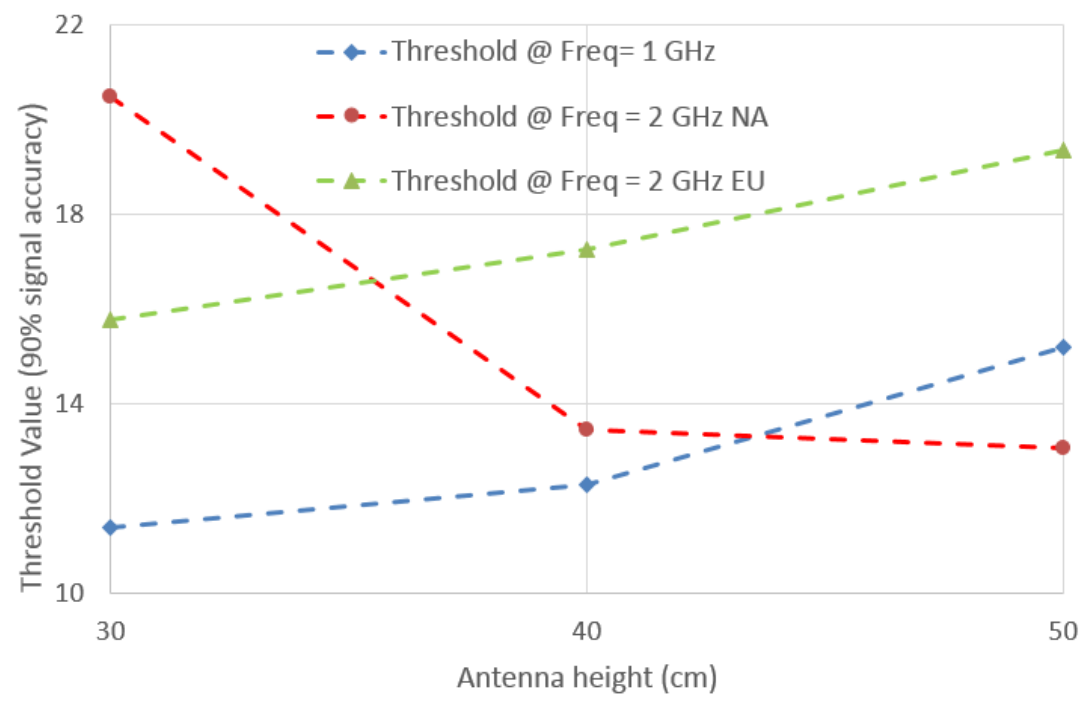

Fig. 12. Threshold values (for a signal accuracy of 90\%) for GPR systems with different antennas $(1 \mathrm{GHz}, 2 \mathrm{GHz} \mathrm{NA}$, and $2 \mathrm{GHz} \mathrm{EU})$ at three heights $(30,40$, and $50 \mathrm{~cm})$ from the metal plate.

The threshold values increase when increasing the heights from the metal plate for the $1 \mathrm{GHz}$ and $2 \mathrm{GHz}$ EU GPR systems, whereas this trend completely changes for the $2 \mathrm{GHz}$ NA. This may 
be likely due to the different characteristics of this system, being the $2 \mathrm{GHz}$ NA a lower powered antenna, whereby clutter is more sensitive to the effects brought by the returns from the target than by the internal system reflections [64 - 67]. When increasing the distance from the reflecting surface, the clutter generated from the interaction between the antenna and the target decreases, thereby leading to progressive lower values of threshold up to a relatively constant value. This may be reasonably related to the single contribution of internal reflections, and turns out to be low due to the less power radiated by antenna.

\section{CONCLUSION}

This paper has devised a signal processing methodology for assessing the performance of the international standard test methods released by the American Society for Testing and Materials (ASTM) about the application of GPR techniques. In particular, we have focused our efforts on the SNR test method proposed by the ASTM Standard D 6087 - 08 ASTM [24]. The theoretical expressions for the bias and variance of the estimation error have been evaluated by a reduced Taylor's expansion up to the second order. Therefore, a closed form expression for theoretically tuning the optimal threshold according to a fixed target value of the GPR signal stability has been proposed. The overall study has been extended to three air-coupled GPR systems with different antennas to analyze the specific relationship between the frequency of investigation, the optimal thresholds, and the signal stability. The results achieved from several trials at the laboratory scale confirm the consistency of such a methodology for assessing the performance of these international standard test methods for GPR systems.

\section{ACKNOWLEDGEMENT}

This work has benefited from the network activities carried out within the EU funded COST Action TU1208 "Civil Engineering Applications of Ground Penetrating Radar". The Authors 
would like also to acknowledge Mr. Spartaco Cera from the Department of Engineering for providing unvaluable help during the experimental tests.

\section{REFERENCES}

[1] Annan A. P., GPR—History, Trends, and Future Developments, Subsurface Sensing Technologies and Applications, Vol. 3, No. 4, 2002, 253-270

[2] Daniels D.J. 2004. Ground Penetrating Radar. The Institution of Electrical Engineers, London.

[3] Benedetto A., Pajewski L. 2015. Civil Engineering Applications of Ground Penetrating Radar. Springer International Publishing. pp. 371. 10.1007/978-3-319-04813-0

[4] Jol H., Ground Penetrating Radar Theory and Application, Elsevier, 2008.

[5] Tosti F., Pajewski L. 2015. Applications of Radar Systems in Planetary Sciences: An Overview. In. Civil Engineering Applications of Ground Penetrating Radar, Benedetto and Pajewski eds. pp. 361-371.

[6] CEI 306-8, Impiego del radar per introspezione del suolo per prospezioni ad opera di posa di servizi ed infrastrutture sotterranee, Comitato Elettrotecnico Italiano, 2004.

[7] IDS Spa, Linee Guida - La tecnologia IDS nel settore GEORADAR, IDS Ingegneria Dei Sistemi, 2001.

[8] ASI, Linee Guida per indagini geofisiche, Associazione Società di Geofisica, 2012.

[9] French Standard NF S70-003-2 (2012): Travaux à proximité des réseaux. Partie 2: techniques de détection sans fouille/Works in the neighborhood of utilities. Part 2: Trenchless techniques of detection.

[10] B 10: Merkblatt über das Radarverfahren zur Zerstörungsfreien Prüfung im Bauwesen, Deutsche Gesellschaft für Zerstörungsfreie Prüfung e.V., DGZfP (2008)

[11] BASt-report B 55.: Überprüfung des Georadarverfahrens in Kombination mit magnetischen Verfahren zur Zustandsbewertung von Brückenfahrbahnplatten aus Beton mit Belagsaufbau, Bundesanstalt für Straßenwesen (2007)

[12] Mara Nord Project.: Recommendations for guidelines for the use of GPR in asphalt air voids content measurement, June 2011

[13] Mara Nord Project.: Recommendations for guidelines for the use of GPR in road construction quality control, June 2011

[14] Mara Nord Project.: Recommendations for guidelines for the use of GPR in bridge deck surveys, June 2011

[15] Mara Nord Project.: The Use of GPR in Road Rehabilitation Projects, June 2011

[16] Mara Nord Project.: Recommendations for guidelines for the use of GPR in Site investigations, June 2011

[17] ETSI EN 301 489-1 v1.9.2, Electromagnetic compatibility and Radio spectrum Matters (ERM); ElectroMagnetic Compatibility (EMC) standard for radio equipment and services; Part 1: Common technical requirements, Sept. 2011, open access on www.etsi.org, Ref. DEN/ERM-EMC-230-32, 45 pp.

[18] ETSI EN 301 489-32 v1.1.1, Electromagnetic compatibility and Radio spectrum Matters (ERM); ElectroMagnetic Compatibility (EMC) standard for radio equipment and services; Part 32: Specific 
conditions for Ground and Wall Probing Radar applications, Sept. 2009, open access on www.etsi.org, Ref. DEN/ERM-EMC-230-32, 12 pp. [8].

[19] ETSI EN 302/066-1 v1.2.1, Electromagnetic compatibility and Radio spectrum Matters (ERM); Ground- and Wall- Probing Radar applications (GPR/WPR) imaging systems; Part 1: Technical characteristics and test methods, Dec. 2007, open access on www.etsi.org, Ref. REN/ERM-TG31A-01131,25 pp. [9].

[20] ETSI EN 302/066-2 v1.2.1, Electromagnetic compatibility and Radio spectrum Matters (ERM); Ground- and Wall- Probing Radar applications (GPR/WPR) imaging systems; Part 2: Harmonized EN covering essential requirements of article 3.2 of the RTTE Directive, Dec. 2007, open access on www.etsi.org, Ref. REN/ERM-TG31A-0113-2, 12 pp. [10].

[21] RTTE Directive 1999/5/EC of the European Parliament and of the Council of 9 March 1999 on radio equipment and telecommunications terminal equipment and the mutual recognition of their conformity. Official Journal L 091 , 07/04/1999 P. 0010 - 0028

[22] ETSI EG 202730 v1.1.1, Electromagnetic compatibility and Radio spectrum Matters (ERM); Code of Practice in respect of the control, use and application of Ground Probing Radar (GPR) and Wall Probing Radar (WPR) systems and equipment, Sept. 2009, open access on www.etsi.org, Ref. DEG/ERM-TGUWB010, 11 pp. [11].

[23] ASTM D6432-11, Standard Guide for Using the Surface Ground Penetrating Radar Method for Subsurface Investigation, ASTM International, West Conshohocken, PA, 2011, www.astm.org, DOI: 10.1520/D6432-11.

[24] ASTM D6087-08, Standard Test Method for Evaluating Asphalt-Covered Concrete Bridge Decks Using Ground Penetrating Radar, ASTM International, West Conshohocken, PA, 2008, www.astm.org, DOI: 10.1520/D6087-08.

[25] ASTM D4748-10, Standard Test Method for Determining the Thickness of Bound Pavement Layers Using Short-Pulse Radar, ASTM International,West Conshohocken, PA, 2010, www.astm.org, DOI: 10.1520/D4748-10.

[26] Zhao A., Jiang Y., and Wang W. 2005. Signal-to-noise ratio enhancement in multichannel GPR data via the Karhunen-Loève transform. Progr. Electromagn. Res., 1(6), pp. 754-757.

[27] Li J., Le Bastard C., Wang Y., Wei G., Ma B., and Sun M. 2016. Enhanced GPR Signal for Layered Media Time-Delay Estimation in Low-SNR Scenario. IEEE Geosci. and Remote Sensing Letters, 13(3), pp. $299-303$.

[28] Travassos X. L., Vieira D. A. G., Palade V. , and Nicolas A. 2009. Noise Reduction in a NonHomogenous Ground Penetrating Radar Problem by Multiobjective Neural Networks. IEEE Trans. on Magnetics, 45(3), pp. 1454-1457.

[29] Bradford J., and Wu Y. 2007. Instantaneous spectral analysis: Time-frequency mapping via wavelet matching with application to contaminated-site characterization by 3D GPR. The Leading Edge, vol. 26, pp. 1018-1023.

[30] Economou N., and Vafidis A. 2010. Spectral balancing GPR data using time variant band-width in t-f domain. Geophysics, 75(3), pp. J19-J27. 
[31] Economou N., and Vafidis A. 2012. GPR data time varying deconvolution by kurtosis maximization. J. of Appl. Geophys., 81, 117-121.

[32] De Pue J., Van Meirvenne M., and Cornelis W. M. 2016. Accounting for Surface Refraction in Velocity Semblance Analysis With Air-Coupled GPR. IEEE J. of Selected Topics in Applied Earth Observations and Remote Sensing, 9(1), pp. 60-73.

[33] Feng X., Yu Y., Liu C., and Fehler M. 2015. Combination of H-Alpha Decomposition and Migration for Enhancing Subsurface Target Classification of GPR. IEEE Trans. Geosci. Remote Sensing, 53(9), pp. 4852-4861.

[34] Gurbuz A. C., McClellan J.H., and Scott Jr. W.R. 2009. Compressive sensing for subsurface imaging using ground penetrating radar., Signal Processing, 89(10), pp. 1959-1972.

[35] Massa A., Boni A., and Donelli M. 2005. A Classification Approach Based on SVM for Electromagnetic Subsurface Sensing. IEEE Trans. Geosci. Remote Sensing, 43(9), pp. 2084-2093.

[36] Rial F. I., Lorenzo H., Novo A., Pereira M. 2011. Checking the Signal Stability in GPR Systems and Antennas. IEEE JSTARS, 4 (4), 785 - 790.

[37] Maser, K.R. and Scullion, T. (1991). "Automated detection of pavement layer thicknesses and subsurface moisture using ground penetrating radar. Transportation Research Board Paper.

[38] Loken, M.C. 2007. "Use of ground penetrating radar to evaluate Minnesota roads", Report MN/RC2007-01, Minnesota Dpt of Transp, Maplewood, MN, USA.

[39] Galagedara L.W., Parkin G.W., Redman J.D., von Bertoldi P. and Endres A.L. 2005. Field studies of the GPR ground wave method for estimating soil water content during irrigation and drainage. Journal of Hydrology 301, 182-197. doi: 10.1016/j.jhydrol.2004.06.031.

[40] Le Gall A., Ciarletti V., Berthelier J.-J., Reineix A., Guiffaut C., Ney R. et al. 2008. An imaging HF GPR using stationary antennas: experimental validation over the Antarctic ice sheet. IEEE Transactions on Geoscience and Remote Sensing 46(12), 3975-3986. doi: 10.1109/ TGRS.2008.2000718.

[41] Tosti, F., and Slob, E.C., Determination, by using GPR, of the volumetric water content in structures, substructures, foundations and soil. Chapter 7 (2015) - In: A. Benedetto \& L. Pajewski (Eds.), Civil Engineering Applications of Ground Penetrating Radar, Springer Transactions in Civil and Environmental Engineering Book Series, 163-194. ISBN 978-3-319-04812-3. DOI 10.1007/978-3-319-04813-0_7.

[42] Benedetto A., Benedetto F. and Tosti F. 2012a. GPR applications for geotechnical stability of transportation infrastructures. Nondestructive Testing and Evaluation 27(3), 253-262. doi: 10589759.2012.694884.

[43] Hugenschmidt J. 2000. Railway track inspection using GPR. Journal of Applied Geophysics 43(2), 147-155. doi: 10.1016/S0926- 9851(99)00054-3.

[44] Al-Qadi I.L., Lahouar S. 2004. Use of GPR for thickness measurement and quality control of flexible pavements. Journal of the Association of Asphalt Paving Technologists 73, 501-528.

[45] Benedetto A. 2010. Water content evaluation in unsaturated soil using GPR signal analysis in the frequency domain. Journal of Applied Geophysics 71, 26-35. doi: 10.1016/j.jappgeo.2010.03.001.

[46] Benedetto A., and Benedetto F. 2011. Remote Sensing of Soil Moisture Content by GPR Signal Processing in the Frequency Domain. IEEE Sensors Journal, vol. 11, no. 10, pp. 2432-2441. 
[47] Scullion T., Lau C.L. and Chen Y. 1994. Pavement evaluations using ground penetrating radar. International Conference on Ground Penetrating Radar. In: Proceedings of the Fifth International Conference on Ground Penetrating Radar, Kitchener, Ontario, Canada, pp. 449-463.

[48] Saarenketo, T., Scullion, T., 2000. Road evaluation with ground penetrating radar. J. Appl. Geophys., 43 (2), 119-138.

[49] Patriarca C., Tosti F., Velds C., Benedetto A., Lambot S. and Slob E.C. 2013. Frequency dependent electric properties of homogeneous multi-phase lossy media in the ground-penetrating radar frequency range. Journal of Applied Geophysics 97, 81-88. doi: 10.1016/j.jappgeo.2013.05.003.

[50] Tosti, F., Benedetto, A., Bianchini Ciampoli, L., Lambot, S., Patriarca, C., and Slob, E.C. 2016. GPR analysis of clayey soil behaviour in unsaturated conditions for pavement engineering and geoscience applications, Near Surface Geophysics 14(2), 127-144,.

[51] Benedetto, F., and Tosti, F. 2013. GPR spectral analysis for clay content evaluation by the frequency shift method, Journal of Applied Geophysics, 1 (97), 89-96.

[52] Huston D.R., Hu J., Maser K., Weedon W. and Adam C. 1999. Ground penetrating radar for concrete bridge health monitoring applications. In: Proceedings of SPIE 3587, pp. 170-179. doi:10.1117/12.339922. [53] Benedetto A., Manacorda G., Simi A. and Tosti F. 2012. Novel perspectives in bridges inspection using GPR. Nondestructive Testing And Evaluation 27(3), 239-251.

[54] Benedetto A., Tosti F., Inferring bearing ratio of unbound materials from dielectric properties using GPR: the case of Runaway Safety Areas, Airfield and Highway Pavement 2013: Sustainable and Efficient Pavements - Proceedings of the 2013 Airfield and Highway Pavement Conference, 2013.

[55] Tosti, F., Adabi, S., Pajewski, L., Schettini, G., and Benedetto, A. 2014. Large-scale analysis of dielectric and mechanical properties of pavement using GPR and LFWD. In: Proceedings of the Fifteenth International Conference on Ground Penetrating Radar, Bruxelles, Belgium, pp. 268-273.

[56] Benedetto, A., Tosti, F., Pajewski, L., D'Amico, F., Kusayanagi, W. FDTD simulation of the GPR signal for effective inspection of pavement damages (2014) Proceedings of the 15th International Conference on Ground Penetrating Radar, GPR 2014, art. no. 6970477, pp. 513-518.

[57] Jacob R. W., and Hermance J. F. 2004. Precision GPR measurements: assessing and compensating for instrument drift. Proc. of the 10th Int. Conf. on Ground Penetrating Radar, vol. 1, pp. 159-162, 2004.

[58] Pereira M., Rial F.I., Lorenzo H., and Arias P. 2005. Analysis and calibration of gpr shielded antennas. Proc. of the $3^{\text {rd }}$ Int. Workshop on Advanced Ground Penetrating Radar, pp. 147 - 151.

[59] Strange A. D. 2013. Analysis of time interpolation for enhanced resolution GPR data", Proc. of the $7^{\text {th }}$ Int Workshop on Advanced Ground Penetrating Radar, pp. 1 - 5.

[60] Carlson A. B., Crilly P. B., and Rutledge J. C. 2002. Communication Systems: An Introduction to Signals and Noise in Electrical Communication. $4^{\text {th }}$ Ed., McGraw-Hill international, NY.

[61] Benedetto, F., Giunta, G. 2011. A fast time-delay estimator of PN signals. IEEE Transactions on Communications, 59 (8), 2057-2062.

[62] Guzzon, E., Benedetto, F., Giunta, G. 2013. A new test for initial code acquisition of correlated cells. IEEE Transactions on Vehicular Technology, 62 (5), 2349-2358. 
[63] Benedetto, F., Giunta, G. 2009. A self-synchronizing method for asynchronous code acquisition in band-limited spread spectrum communications. IEEE Transactions on Communications, 57 (8), 2410-2419. [64] Olhoeft G. R. 2002. The new ground-penetrating radar regulatory environment. Proc. SPIE 4758, 9th Int. Conf. on Ground Penetrating Radar.

[65] Feigin J., Roberts R., and Parrillo R. 2010. Noise and Interference Reduction in Air-Launched Antennas used for GPR Evaluation of Roads and Bridges. Proc. of the Structural Materials Technology Conf.

[66] EUWB consortium, 2011. Ultra-Wideband: Past, Present and Future (White Paper). http://www.euwb.eu/

[67] Federal Communications Commission (FCC) Regulations. USA regulations on UWB GPR, Section 15, Ch. I (10-1-09 Edition). 